\title{
Thyroid hormone regulates protease expression and activation of Notch signaling in implantation and embryo development
}

\author{
Diletta Piccirilli1,*, Enke Baldini2,*, Micol Massimiani', Antonella Camaioni', Antonietta Salustri', \\ Roberta Bernardini³, Marco Centanni4, Salvatore Ulisse ${ }^{2}$, Costanzo Moretti5 and Luisa Campagnolo \\ 'Department of Biomedicine and Prevention, University of Rome Tor Vergata, Rome, Italy \\ 2Department of Surgical Sciences, 'Sapienza' University of Rome, Rome, Italy \\ 3Department of Biology, NSTA, II University of Rome, Tor Vergata, Italy \\ 4Department of Medico-Surgical Sciences and Biotechnologies, 'Sapienza' University of Rome, Latina, Italy \\ ${ }^{5}$ Department of Systems' Medicine University of Rome Tor Vergata, UOC of Endocrinology and Diabetes, Section of Reproductive Endocrinology \\ Fatebenefratelli Hospital, 'Isola Tiberina', Rome, Italy
}

Correspondence should be addressed to L Campagnolo: campagnolo@med.uniroma2.it

*(D Piccirilli and E Baldini contributed equally to this work)

\section{Abstract}

A clinical association between thyroid dysfunction and pregnancy complications has been extensively reported; however, the molecular mechanisms through which TH might regulate key events of pregnancy have not been elucidated yet. In this respect, we performed in vivo studies in MMl-induced hypothyroid pregnant mice, evaluating the effect of hypothyroidism on the number of implantation sites, developing embryos/ resorptions and pups per litter, at 4.5, 10.5, 18.5 days post-coitum (dpc) and at birth. We also studied the expression of major molecules involved in implantation and placentation, such as the proteases ISPs, MMPs, TIMPs and Notch pathway-related genes. Our results demonstrate that hypothyroidism may have a dual effect on pregnancy, by initially influencing implantation and by regulating placental development at later stages of gestation. To further elucidate the role of $\mathrm{TH}$ in implantation, we performed in vitro studies by culturing $3.5 \mathrm{dpc}$ blastocysts in the presence of $\mathrm{TH}$, with or without endometrial cells used as the feeder layer, and studied their ability to undergo hatching and outgrowth. We observed that, in the presence of endometrial feeder cells, TH is able to anticipate blastocyst hatching by upregulating the expression of blastocystproduced ISPs, and to enhance blastocyst outgrowth by upregulating endometrial ISPs and MMPs. These results clearly indicate that TH is involved in the bidirectional crosstalk between the competent blastocyst and the receptive endometrium at the time of implantation.

\author{
Key Words \\ - blastocyst \\ thyroid hormone \\ - placenta \\ - proteases \\ - implantation
}

Journal of Endocrinology (2018) 236, 1-12

\section{Introduction}

Embryo implantation is one of the earliest and critical events of the mammalian reproduction. It occurs in the maternal uterus and allows the mother to nourish and protect the embryo during its subsequent development, determining whether pregnancy will develop successfully. Once arrived in the uterus, the embryo has reached 
the blastocyst stage and it is still protected by the zona pellucida (ZP), which prevents extra-ectopic implantation. In order to implant, the blastocyst has to hatch from the ZP. Hatching needs to occur in a well-defined timeframe, the window of implantation, when the molecular program regulating growth and differentiation of the embryo synchronizes with the molecular program regulating endometrial receptivity. Blastocyst hatching is a finely regulated process of crucial importance for the subsequent development of the embryo, allowing attachment of the blastocyst to the maternal tissue. Any dysregulation in the hatching process can lead to implantation failure and infertility (Petersen et al. 2005).

The hatching process is subject to both cellular and molecular controls and it begins with the formation of a nick in the ZP, in which the mechanical pressure exerted by the expanding blastocyst is involved. However, it has been demonstrated that hatching is not just a passive process that follows blastocyst expansion, but it also involves several regulatory molecules, which include growth factors (e.g. EGF, HB-EGF, TGF-B and LIF) (Mishra \& Seshagiri 2000, Seshagiri et al. 2002), and the local production of potential zona-lysins, involved in the digestion of the ZP, produced by both the embryo and the endometrium (Vu et al. 1997, Mishra \& Seshagiri 2000). These proteases may play a crucial role in the formation of the nick into the ZP. Recently, studies on mouse implantation have identified two new proteinases associated with hatching: Strypsin (ISP1) and Lysin (ISP2) (O'Sullivan et al. 2001, Sharma et al. 2006). ISP1 and ISP2 are two related S1-family serine proteinases localized on mouse chromosome 17. Isp1 and Isp2 genes are co-expressed in pre-implantation embryos and in the mouse uterine endometrium during the 'window of implantation' (O'Sullivan et al. 2001, Sharma et al. 2006, 2011). Sharma and coworkers have demonstrated a crucial role of ISPs, as antibodies against ISP1/ISP2 have been found to block murine embryo hatching and outgrowth (O'Sullivan et al. 2001).

Once escaped from the ZP, the embryo attaches to the uterine endometrium and trophoblast cells invade the endometrial tissue (Aplin et al. 2000, Kaneko et al. 2013) and contribute to the formation of the placenta, which is indispensable for the survival and growth of the embryo. Molecules involved in trophoblast invasion and placentation include growth factors and cytokines (EGF, HB-EGF, LIF and IL-1), hormones (hCG and progesterone), MMPs (which degrade the extracellular matrix of the uterine endometrium) and TIMPs (which limit the extent of trophoblast invasion). The balance between MMPs and TIMPs strongly influences the process of invasion (Staun-Ram \& Shalev 2005).

Among the hormones involved in the regulation of mammalian reproduction, thyroid hormone (TH) has been one of the most debated. THs are essential for the correct development, growth and metabolism of the body, in particular during fetal development and early childhood (Schwartz et al. 1983, Contempre et al. 1993, Chan \& Kilby 2000, Dittrich et al. 2011, Moeller \& Broecker-Preuss 2011). Interestingly, TH function during development is not limited to the stages during which fetal thyroid gland is present and functional, but also when it is absent or developing (Thorpe-Beeston et al. 1991, Krassas et al. 2010), implying a role for maternal $\mathrm{TH}$ on fetal development. Both hypothyroidism and hyperthyroidism have been associated with subfertility and recurrent miscarriage (Obregon et al. 1984, van den Boogaard et al. 2011). Several studies have demonstrated that producing and maintaining optimal levels of THs are fundamental during pregnancy for both mother and fetus and that TH-metabolizing enzymes are detectable already during the implantation stage, suggesting a putative regulatory role during early embryo development (Thorpe-Beeston et al. 1991, Ashkar et al. 2010); however, TH functions during the early stages of embryo development are not clearly understood.

It has been recently demonstrated that supplementation of $\mathrm{TH}$ has a beneficial effect on bovine embryo development in vitro (Aghajanova et al. 2011, Costa et al. 2013). In vivo, thyroid hormone receptor (TR) and thyrotropin receptor are expressed in the endometrium, and their expression in endometrial cells is concomitant with the appearance of pinopodes and the establishment of the endometrial receptivity (Idris et al. 2005).

The placenta, responsible for the exchange of oxygen, nutrients, hormones, growth factors and their waste products between mother and fetus and essential for a normalfetaldevelopment, regulates the transfer of maternal THs to the fetal circulation and protects the developing fetus from toxic concentration of THs. Besides facilitating transplacental TH transport, the placenta is a target organ for $\mathrm{TH}$ action and is sensitive to $\mathrm{TH}$ for the regulation of its metabolism, differentiation and development. Maternal hyperthyroidism and hypothyroidism may associate with pregnancy complications including miscarriages, reduced birth weight, intrauterine growth restriction (IUGR), pre-eclampsia and spontaneous abortion (Kumar \& Chaudhuri 1989, Abalovich et al. 2002, Mestman 2004, Casey et al. 2005, LaFranchi et al. 2005, Kilby et al. 2005, Pillar et al. 2010, Luewan et al. 2011). Studies 
using animal models of hypothyroidism have provided further evidence for the importance of THs in placental development. In rats, maternal hypothyroidism resulted in impaired reproduction and IUGR (Ashitaka et al. 1988, Nazarpour et al. 2015). The human placenta expresses a range of TH transporters, DIO and TR, which modulate TH availability and metabolism (Banovac et al. 1986, Kilby et al. 1998, Chan et al. 2003). In vitro, stimulation of placental explants by TH causes an increased secretion of progesterone, estradiol-17B and hCG (Maruo et al. 1991). These data suggest that the physiological level of TH may be essential in regulating placental endocrine activity during pregnancy. Based on these pieces of evidence, in the present work, we performed in vivo studies, evaluating the effect of hypothyroidism on implantation, placentation and the expression of the major molecules involved in these processes, such as MMPs, TIMPs and Notch target genes. In parallel, we performed in vitro studies to investigate if $\mathrm{TH}$ may be involved in embryo implantation, focusing on the regulation of blastocyst hatching from the ZP and its outgrowth.

\section{Materials and methods}

\section{Animals}

6-week-old CD1 mice were obtained from Charles River. Mice were housed and mated under standard conditions with controlled light cycle (lights-on between 07:00 h and $19: 00 \mathrm{~h})$ and temperature $\left(20^{\circ} \mathrm{C}\right)$, and treated using humane care in order to inflict the least possible pain. All experiments were approved by Institutional Animal Care and Use Committee of the Tor Vergata University and the Italian Ministry of Health (approval date October 17th 2013; prot. n.32/2013), and carried out according to the Italian and European rules (D.L.116/92; C.E. 609/86; European Directive 2010/63/EU).

\section{In vivo experiments}

To induce hypothyroidism, groups of 10 CD1 females were treated with $2 \mathrm{mg} / \mathrm{mL}$ Methimazole (MMI) (SigmaAldrich) dissolved in drinking water for 8 weeks. The MMI solution was replaced thrice a week. To evaluate TH-circulating levels, serum was collected after retroorbital bleeding and assayed using an ELISA commercial kit, following the manufacturer's specification (SigmaAldrich). Hypothyroid and control females were housed overnight with males of proven fertility, and the presence of a vaginal plug assessed the following morning. Before mating, the phase of the estrus cycle of each female was determined by visual inspection of the external genitalia, and only females in proestrus or estrus were selected. Midday of the day on which the vaginal plug was found was considered day 0.5 of pregnancy $(0.5 \mathrm{dpc})$. Pregnant animals were killed at $4.5,10.5$ and $18.5 \mathrm{dpc}$ by cervical dislocation, or allowed to give birth. MMI treatment was maintained until they were killed. For the visualization of implantation sites ( $4.5 \mathrm{dpc}), 100 \mu \mathrm{L}$ of $10 \mathrm{mg} / \mathrm{mL}$ Chicago blue dye (Sigma-Aldrich) in saline solution was injected in the retro-orbital plexus of pregnant females. After $10 \mathrm{~min}$, females were killed and the uterus was analyzed for the presence of blue spots. Implantation and interimplantation sites were independently collected, flashfrozen and stored at $-80^{\circ} \mathrm{C}$ for further analysis. Similarly, placentas from 10.5- and $18.5 \mathrm{dpc}$ females were collected.

\section{Preparation of endometrial cell cultures}

Endometrial cells were obtained by enzymatic digestion of competent uteri from $3.5 \mathrm{dpc}$ pregnant females. In detail, after flushing the embryos out, uterine horns were squeezed using forceps and the resulting tissue incubated with a solution of $1 \mathrm{mg} / \mathrm{mL}$ collagenase (Sigma-Aldrich), $0.5 \mathrm{mg} / \mathrm{mL}$ hyaluronidase (Sigma-Aldrich) and $0.05 \mathrm{mg} / \mathrm{mL}$ DNase (Sigma-Aldrich) in Dulbecco's modified Eagle's medium/Ham's F12 medium (DMEM/F12, Lonza, Milan, Italy) (1:1) supplemented with $2 \mathrm{mM}$ L-glutamine, $50 \mathrm{U} / \mathrm{mL}$ penicillin, $50 \mathrm{U} / \mathrm{mL}$ streptomycin, $20 \mathrm{mM}$ Hepes (Lonza) and $10 \%(\mathrm{v} / \mathrm{v})$ fetal bovine serum (Lonza), for $30 \mathrm{~min}$ at $37^{\circ} \mathrm{C}$. After centrifugation and washing with phosphate buffered saline (Lonza), endometrial cells were cultured in 4-well Nunc plates (Thermo Fisher Scientific) in DMEM/F12 complete medium at $37^{\circ} \mathrm{C}$ and $5 \% \mathrm{CO}_{2}$.

\section{In vitro hatching and outgrowth assays}

Blastocysts were collected from 3.5 dpc pregnant females by flushing the uterine horns with DMEM/F12 complete medium.

For each experiment, an average number of 30 blastocysts was cultured in presence or absence of endometrial cells in DMEM/F12 complete medium (Lonza) at $37^{\circ} \mathrm{C}$ and $5 \% \mathrm{CO}_{2}$, in 4-well Nunc cell culture multi-dishes (Thermo Fisher Scientific). Blastocysts and endometrial cells were treated with $100 \mathrm{ng} / \mathrm{mL}$ L-thyroxine ( $\mathrm{T}_{4}$ ) (Sigma-Aldrich) for 16, 48 and $72 \mathrm{~h} . \mathrm{T}_{4}$ was dissolved in DMSO (Sigma-Aldrich) at the concentration of $2.5 \mathrm{mg} / \mathrm{mL}$ (stock solution). The working solution was 
prepared with DMEM/F12 complete medium. The untreated group was administered with an equal volume of DMSO as control.

Blastocyst hatching and outgrowth was monitored at the indicated time points and photographed using a Leitz Diavert microscope connected to a Nikon DS-Fi1 camera. Hatching was calculated as the number of hatched blastocysts after 16, 24 and 48 h of culture on the total number of cultured blastocysts, and reported as a percentage. Blastocysts' outgrowth was estimated in terms of covered area (pixels), using the ImageJ Software.

\section{RNA isolation and quantitative RT-PCR}

Total RNA from tissues and cell cultures was prepared using the TRIZOL Reagent (Roche Diagnostics GmbH) according to the manufacturer's protocol. Possible DNA contamination was removed by DNAse treatment. RNA quality was examined on agarose gels. mRNA was reversetranscribed using Quantitect Reverse Transcription Kit (Qiagen) following the manufacturer's protocol. Specific primers for murine Mmp2, Mmp3, Mmp9, Mmp10, Mmp11, Isp1, Isp2, Hes1, Hey1, Hey2, Timp1, Timp2, Timp3 and Gapdh were designed using the Primer Express software (Applied Biosystems in Life Technologies). Primer sequences are listed in Table 1 . The gene expression analysis was performed using Real Master Mix SYBR ROX (Kapa Biosystems, Boston, MA, USA). Differences among the gene expression were quantified using the $\Delta \Delta \mathrm{Ct}$ method with normalization to Gapdh.

\section{Statistical analysis}

Data were collected from at least three independent experiments and analyzed with Graph-pad Prism 6.0 software. Data are presented as mean \pm s.E.M. $P$ value was determined by $T$-test and Chi-square test. Statistical significance was based on $P$ value: ${ }^{*} P<0.05,{ }^{* *} P \leq 0.01$, ${ }^{* * *} P \leq 0.001,{ }^{* * * *} P<0.0001$.

\section{Results}

\section{TH effect on pregnancy outcome}

To evaluate the role of TH on pregnancy, we induced hypothyroidism in CD1 females by administration of the thyroid peroxidase inhibitor MMI. Reduction of circulating levels of $\mathrm{T}_{4}$ was confirmed by ELISA assay. In control non-MMI-treated mice, the serum level of $\mathrm{T}_{4}$ was
Table 1 Primer sets for qRT-PCR.

\begin{tabular}{|c|c|c|c|}
\hline Gene & Direction & Sequence & $\begin{array}{l}\text { Produ } \\
\text { size }\end{array}$ \\
\hline \multirow[t]{2}{*}{ Mmp2 } & $\overline{\text { Forward }}$ & CCCATGAAGCCTTGTTTACCA & $85 b p$ \\
\hline & $\operatorname{Re}$ & GGAGGTGCCCTGGAA & \\
\hline \multirow[t]{2}{*}{ Mmp3 } & Forward & TGATGAACGATGGACAGAGGAT & $100 \mathrm{bp}$ \\
\hline & Reverse & AGCCTTGGCTGAGTGGTAGAGT & \\
\hline \multirow[t]{2}{*}{ Mmp9 } & Forward & GATGTTTTTGATGCTATTGCTGAGA & $64 \mathrm{bp}$ \\
\hline & Reve & AGTACCAACCGTCCTTGAAGAAAT & \\
\hline \multirow[t]{2}{*}{ Mmp10 } & Forward & СCACTCACTTTCTCCAGGATCTCT & $70 \mathrm{bp}$ \\
\hline & Reverse & CGTGTTCTCCAACTGCAAAGG & \\
\hline \multirow[t]{2}{*}{ Mmp11 } & Forward & TCCCTAAGACCCACCGAGAA & $83 \mathrm{bp}$ \\
\hline & Reverse & CAGGTCAGTTCCCTGGTTGTC & \\
\hline \multirow[t]{2}{*}{ Isp1 } & Forward & AACTCCTGGGTGCACATCTGT & $88 \mathrm{bp}$ \\
\hline & & CTGACTTTGGAT & \\
\hline \multirow[t]{2}{*}{ Isp2 } & Forward & GGGCACACCCACATCTTTTG & $93 b p$ \\
\hline & $\operatorname{Re}$ & TCA & \\
\hline \multirow[t]{2}{*}{ Hes1 } & Forward & AGAAA & $65 b$ \\
\hline & & GTG & \\
\hline \multirow[t]{2}{*}{ Hey1 } & Forward & GACGGAGAGGCATCATCGA & $65 \mathrm{bp}$ \\
\hline & Reverse & TCTCAGCTCAGACAAACTGTTATTGA & \\
\hline \multirow[t]{2}{*}{ Hey2 } & Forward & TTACCCTGGGCACGCTACA & $72 \mathrm{bp}$ \\
\hline & Reverse & CTTGCCATAATCTGAGAGG TAGTTGT & \\
\hline \multirow[t]{2}{*}{ Timp1 } & Forward & CCCAGAACCGCAGTGAAGAG & $68 \mathrm{bp}$ \\
\hline & & GGCACTGATGTGCAAATTTCC & \\
\hline \multirow[t]{2}{*}{ Timp2 } & Forward & GCAATGCAGACGTAGTGATCAGA & $59 \mathrm{bp}$ \\
\hline & & CCCGGAATCCACCTCCTT & \\
\hline \multirow[t]{2}{*}{ Timp3 } & Forward & CACACGGAAGCCTCTGAAAGT & $82 \mathrm{~b}$ \\
\hline & & CATACACGCGCCCTGTCA & \\
\hline \multirow[t]{2}{*}{ Gapdh } & Forward & AACTTTGGCATTGTGGAAGG & $222 b p$ \\
\hline & Reverse & CACATTGGGGGTAGGAACAC & \\
\hline
\end{tabular}

$6.6 \pm 1.7 \mu \mathrm{g} / \mathrm{dL}$, while in mice treated with MMI, the level was reduced to about $1 / 3(2 \pm 0.26 \mu \mathrm{g} / \mathrm{dL}$; Fig. $1 \mathrm{~A})$.

After confirming that hypothyroidism was induced, females were mated and pregnancy was monitored up to delivery, when the number of pups per litter was counted. A clear association between reduced circulating levels of $\mathrm{T}_{4}$ and a significant reduction in the number of pups with respect to control was observed $(\mathrm{CTRL}=12.50 \pm 0.97$; $\mathrm{MMI}=6.4 \pm 1.66$; Fig. 1B). To identify the developmental stage at which hypothyroidism was affecting embryo development, we killed pregnant females at different
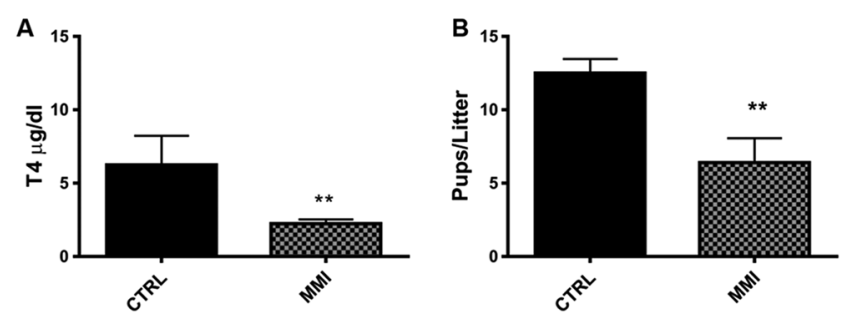

Figure 1

MMI treatment induces hypothyroidism in CD1 females and reduces the number of pups/litter. (A) Dosage of total $T_{4}$ in the serum of controls and MMI-treated females, and (B) average number of pups/litter in control and MMI-treated hypothyroid females (number of animals analyzed, $n=10) . * * P \leq 0.01$. 

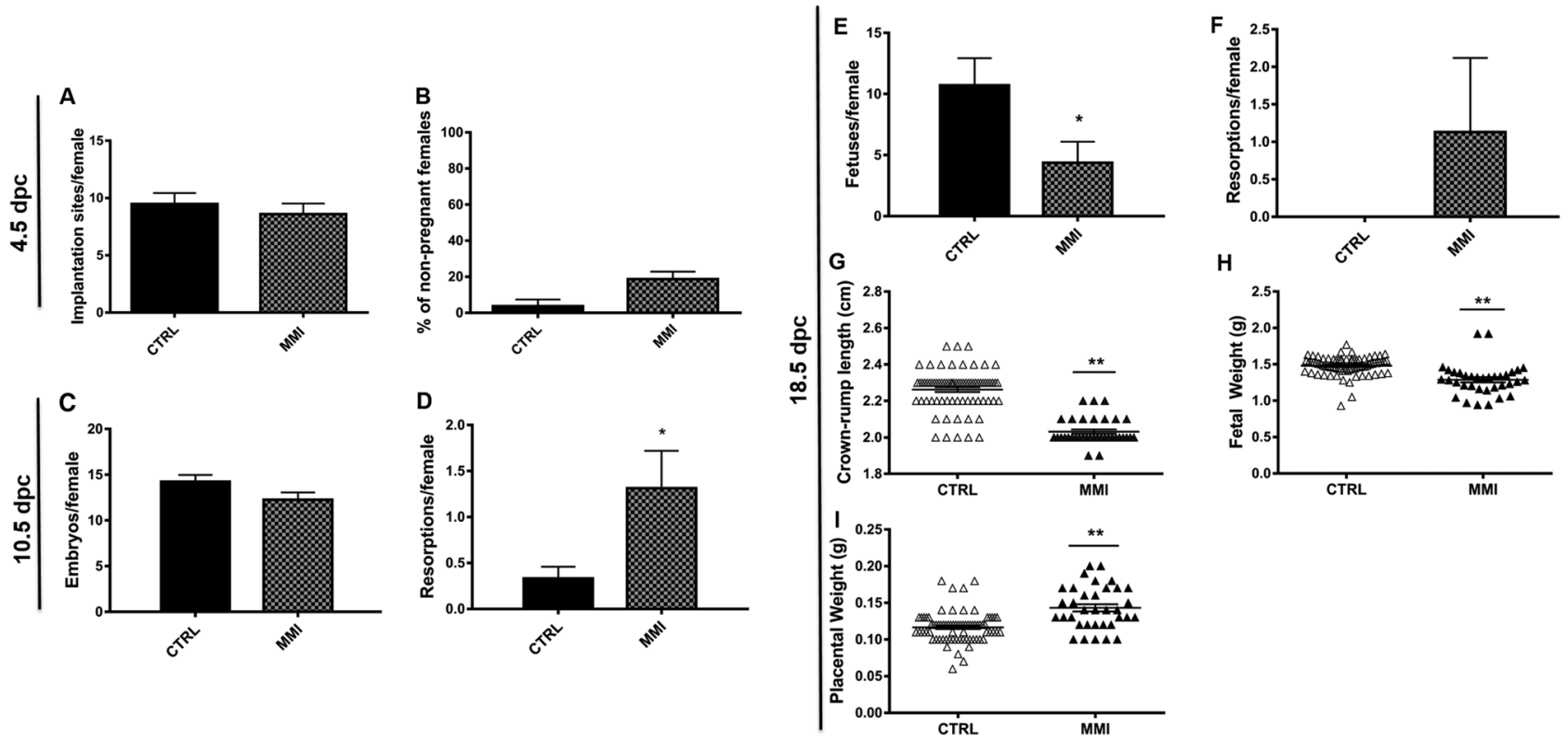

Figure 2

Hypothyroidism influences pregnancy outcome. (A) Average number of implantation sites in control and MMI-treated females at $4.5 \mathrm{dpc}$ (B) Percentage of pregnant vs non-pregnant females in control and MMI-treated mice assessed at $4.5 \mathrm{dpc} ; P=0.052\left(n_{\mathrm{ctrl}}=25 ; n_{\mathrm{MMI}}=22\right)$. (C, D, E and F) Comparison of the number of embryos and resorptions per female in controls and hypothyroid females at $10.5 \mathrm{dpc}\left(\mathrm{C}\right.$ and $\left.\mathrm{D} ; n_{\mathrm{ctrl}}=18 ; n_{\mathrm{MMI}}=15\right)$ and $18.5 \mathrm{dpc}(\mathrm{E}$ and $\mathrm{F} ;$ $n_{\mathrm{ctrl}}=7 ; n_{\mathrm{MMI}}=8$ ); ( $\mathrm{D}$ and $\left.\mathrm{E}\right) \mathrm{P}<0.05$. (G, H and I) Maternal hypothyroidism affects embryonic development at $18.5 \mathrm{dpc}$, influencing crown-rump length (G) fetal weight $(\mathrm{H})$ and placental weight $(\mathrm{I}) .{ }^{*} P \leq 0.01$

gestational stages, from implantation $(4.5 \mathrm{dpc})$ up to 18.5 dpc. First, we investigated if decreased circulating levels of $\mathrm{T}_{4}$ affected implantation. To this end, we mated females, verified the presence of the plug and counted the number of implantation sites in the uterus at $4.5 \mathrm{dpc}$. At this developmental stage, we did not observe a significant difference in the number of implantation sites in the uteri of hypothyroid females $(\mathrm{CTRL}=9.5 \pm 0.9 ; \mathrm{MMI}=8.6 \pm 0.9$; Fig. 2A); however, the percentage of non-pregnant mice in the MMI-treated group was about five-fold higher than that of the control group, although the difference did not reach statistical significance $\quad(\mathrm{CTRL}=3.7 \pm 3.7 \% ; \quad \mathrm{MMI}=18.67 \pm 4.1 \%$; Fig. 2B). To investigate if hypothyroidism influences placental development, pregnant females were killed at $10.5 \mathrm{dpc}$, a critical time point for mouse placentation (Watson \& Cross 2005). We observed a slight, but non-significant decrease in the number of embryos $(\mathrm{CTRL}=14.22 \pm 0.75 ; \quad \mathrm{MMI}=12.25 \pm 0.81 ; \quad$ Fig. 2C), accompanied by a concomitant significant increase in the number of fetal resorptions $(C T R L=0.33 \pm 0.13$; $\mathrm{MMI}=1.31 \pm 0.40$; Fig. 2D). At a later developmental stage, close to parturition $(18.5 \mathrm{dpc})$, we detected a significant reduction in the number of fetuses in the hypothyroid group $(\mathrm{CTRL}=10.71 \pm 2.2 ; \quad \mathrm{MMI}=4.37 \pm 1.72 ; \quad$ Fig. $2 \mathrm{E})$, which was associated with an increase in fetal resorptions
$(\mathrm{CTRL}=0 ; \mathrm{MMI}=1.13 \pm 0.99 ;$ Fig. $2 \mathrm{~F})$. We also observed a significant reduction in fetal weight $(\mathrm{CTRL}=1.5 \pm 0.01 \mathrm{~g}$; $\mathrm{MMI}=1.2 \pm 0.03 \mathrm{~g} ;$ Fig. 2G) and crown-rump length $(\mathrm{CTRL}=2.3 \pm 0.01 \mathrm{~cm} ; \mathrm{MMI}=2.03 \pm 0.01 \mathrm{~cm}$; Fig. $2 \mathrm{H})$ and a slight increase in placental weight in the hypothyroid
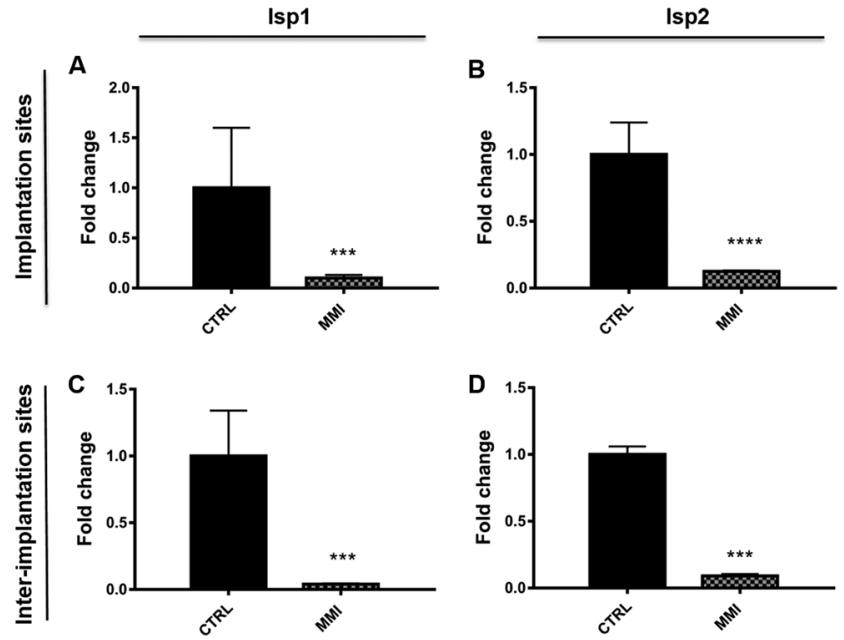

Figure 3

Hypothyroidism induces a significant reduction of ( $A$ and $C$ ) Isp1 and ( $B$ and $D$ ) Isp2 gene expressions in implantation ( $A$ and $B$ ) and interimplantation (C and D) sites. $* * * P \leq 0.001, * * * * P \leq 0.0001$; Data are the mean of five independent experiments \pm S.E. 


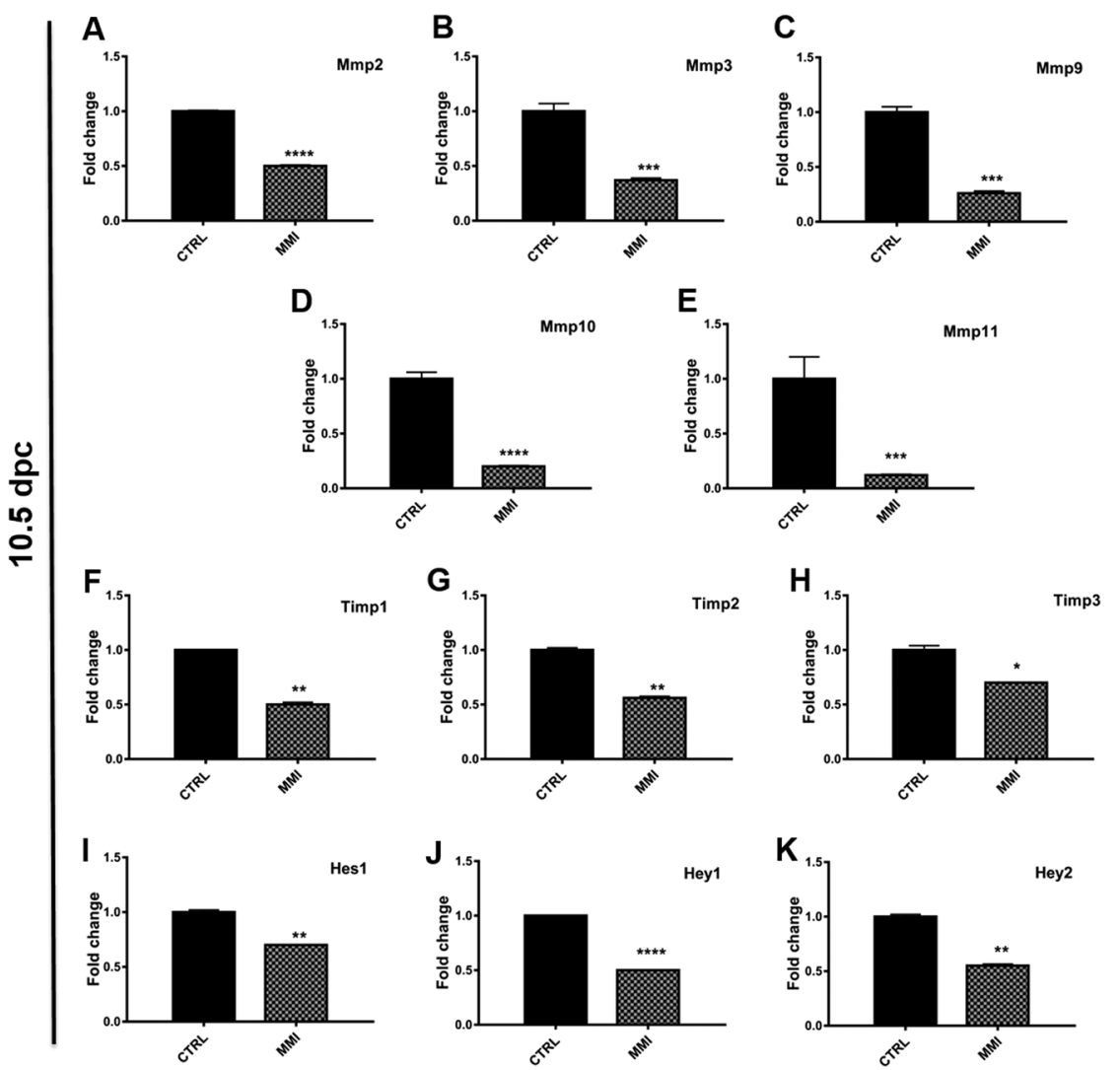

\section{Figure 4}

Maternal hypothyroidism affects placental expression of MMPs (A, B, C, D and E) and TIMPs $(F, G$ and $H)$ and of Notch target genes $(I, J$ and $K)$ at $10.5 \mathrm{dpc}$. (A) Expression of Mmp2, (B) Mmp3, (C) Mmp9, (D) Mmp10, (E) Mmp11, (F) Timp1, (G) Timp2, (H) Timp3, (I) Hes1, (J) Hey1 and (K) Hey2 in placentas from euthyroid and hypothyroid females. $* P<0.05 ; * * P \leq 0.01, * * * P \leq 0.001$, $* * * * P \leq 0.0001$. Data are the mean of four independent experiments \pm S.E. females compared to controls $(\mathrm{CTRL}=0.12 \pm 0.002 \mathrm{~g}$; $\mathrm{MMI}=0.14 \pm 0.005 \mathrm{~g}$; Fig. 2I).

\section{Molecular pathways affected by reduced levels of TH}

Based on the observation that hypothyroidism influences embryo/fetal development, we investigated molecular pathways involved in implantation and placental development, which responded to the reduced circulating levels of TH. To this end, we performed the gene expression analysis of implantation sites $(4.5 \mathrm{dpc})$ and of $10.5 \mathrm{dpc}$ and $18.5 \mathrm{dpc}$ placentas. In $4.5 \mathrm{dpc}$ implantation and interimplantation sites, we analyzed the expression of Isp1 and Isp2, two mouse-specific serine proteinases expressed by both the blastocyst and the endometrium during the 'window of implantation'. Quantitative RT-PCR analysis revealed a significant reduction in the expression of Isp1 and Isp 2 in both implantation and inter-implantation sites collected from hypothyroid females compared to euthyroid females (Fig. 3). In $10.5 \mathrm{dpc}$ placentas, we investigated the expression of matrix metalloproteinases 2, 3, 9, 10 and 11 (MMPs), involved in placental

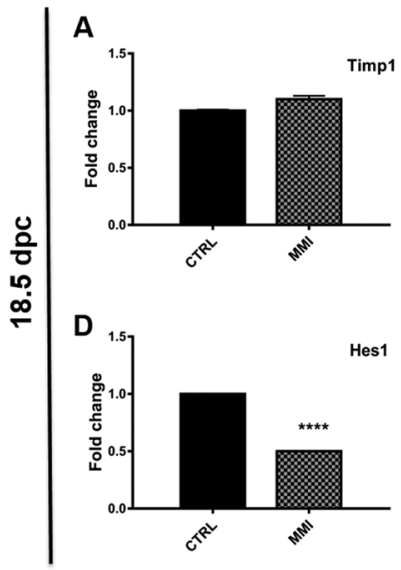

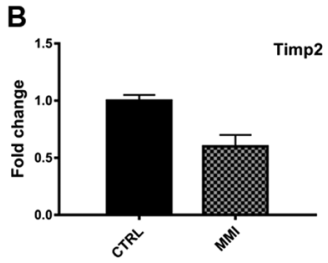
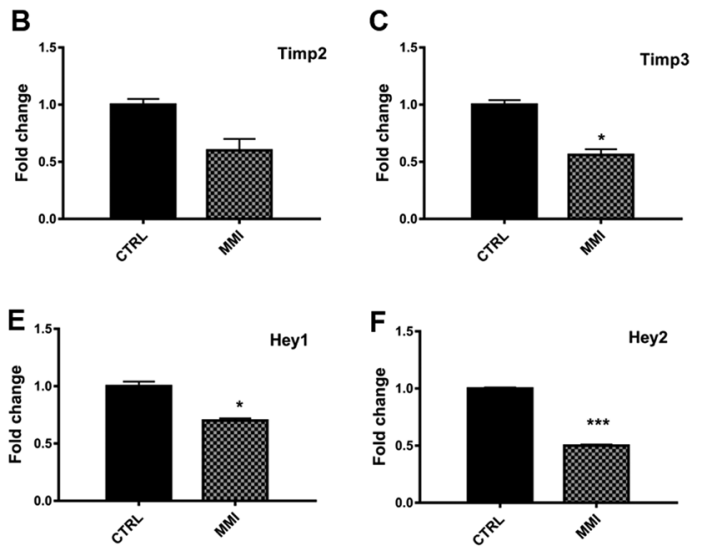

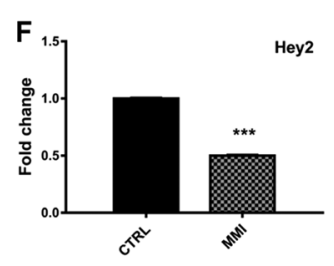

Figure 5

Hypothyroidism reduces placental expression of Timp3 and Notch target genes at $18.5 \mathrm{dpc}$. Relative expression of Timp1 (A), Timp2 (B) and Timp3 (C) and Notch target genes Hes1 (D), Hey1 (E) and Hey2 (F) in placentas collected from 18.5 hypothyroid and euthyroid $C D 1$ females. $* P<0.05, * * * P \leq 0.001, * * * * P \leq 0.0001$. Data are the mean of three independent experiments \pm S.E. 
A 1 Endometrial cells
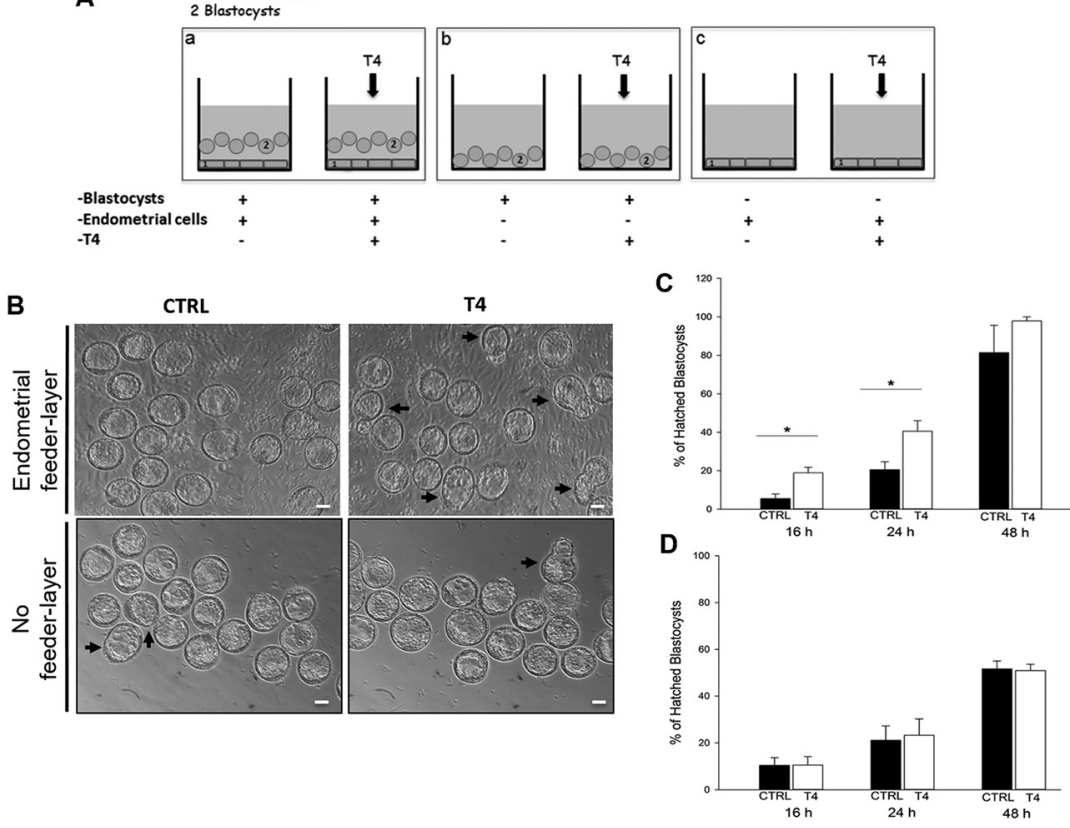

\begin{abstract}
Figure 6
TH supplementation stimulates mouse blastocyst hatching in vitro. (A) Schematic representation of the in vitro model developed to assess TH role in implantation. (a) Co-culture of murine blastocysts and endometrial primary cells as the feeder layer; (b) blastocysts cultured on plastic; (c) endometrial cells cultured without blastocysts. (B) Representative images of the cultures. Scale bar $50 \mu \mathrm{m}$. (C and D) Graphs summarizing the results shown in B: percent of hatched blastocysts after co-culture on endometrial cells (C) $\left(n_{\mathrm{ctrl}}=771 ; n_{\mathrm{T} 4}=762\right)$ or on plastic (D) $\left(n_{\mathrm{ctrl}}=154 ; n_{\mathrm{T} 4}=162\right) .{ }^{*} P<0.05$.
\end{abstract}

morphogenesis, tissue inhibitor of metalloproteinases 1 , 2 and 3 (TIMPs), which function as modulators of tissue remodeling, and Notch target genes Hes1, Hey1 and Hey2, required for trophoblast function, and placental angiogenesis. All MMPs, TIMPs and Notch target genes analyzed resulted significantly downregulated in 10.5 dpc placentas collected from hypothyroid pregnant females (Fig. 4). Timp3 and Notch target genes were also significantly downregulated in placentas collected from 18.5 dpc hypothyroid females (Fig. 5).

\section{TH role on blastocyst implantation in vitro}

We further investigated the role of $\mathrm{TH}$ on embryo implantation by in vitro culturing blastocysts collected from $3.5 \mathrm{dpc}$ control pregnant females, either on plastic or on endometrial primary cells, with or without supplementation of $100 \mathrm{ng} / \mathrm{mL}$ of $\mathrm{T}_{4}$ (Fig. 6A, B, C and $\mathrm{D})$. The number of blastocysts hatching from the $\mathrm{ZP}$ was counted after 16, 24 and $48 \mathrm{~h}$ of culture. Our results show that supplementation of the blastocyst/endometrium
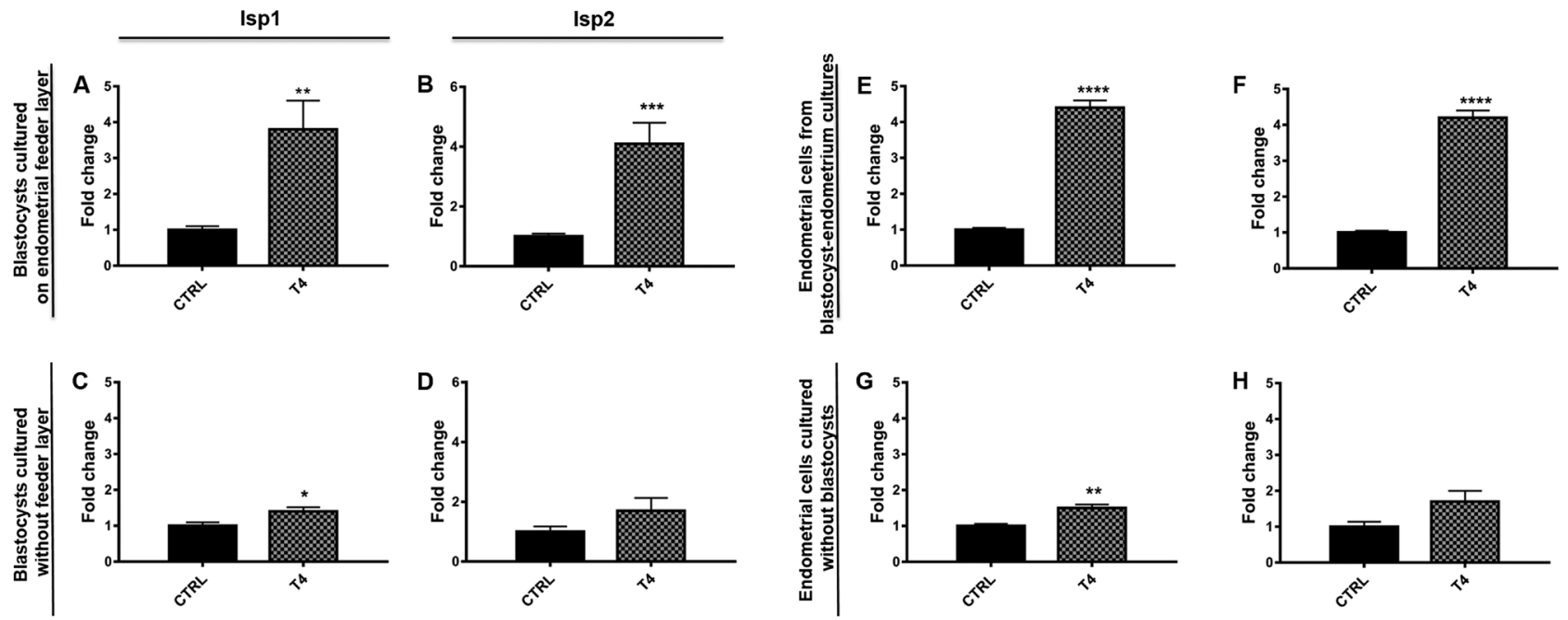

Figure 7

Blastocyst-endometrium interaction is indispensable for TH-mediated increase in the expression of the serine proteases Isp1 and Isp2. Isp1 and Isp2 expressions in blastocysts cultured with or without $T_{4}$ supplementation on endometrial feeder layer (A and B) or plastic (C and D). Isp1 and Isp2 expressions in endometrial cells co-cultured with blastocysts ( $E$ and $F$ ) or cultured alone $(G$ and $H)$, with or without $T_{4}$ supplementation. ${ }^{*} P<0.05$, $* * P \leq 0.01, * * * P \leq 0.001$. Data are the mean of four independent experiments \pm S.E. 

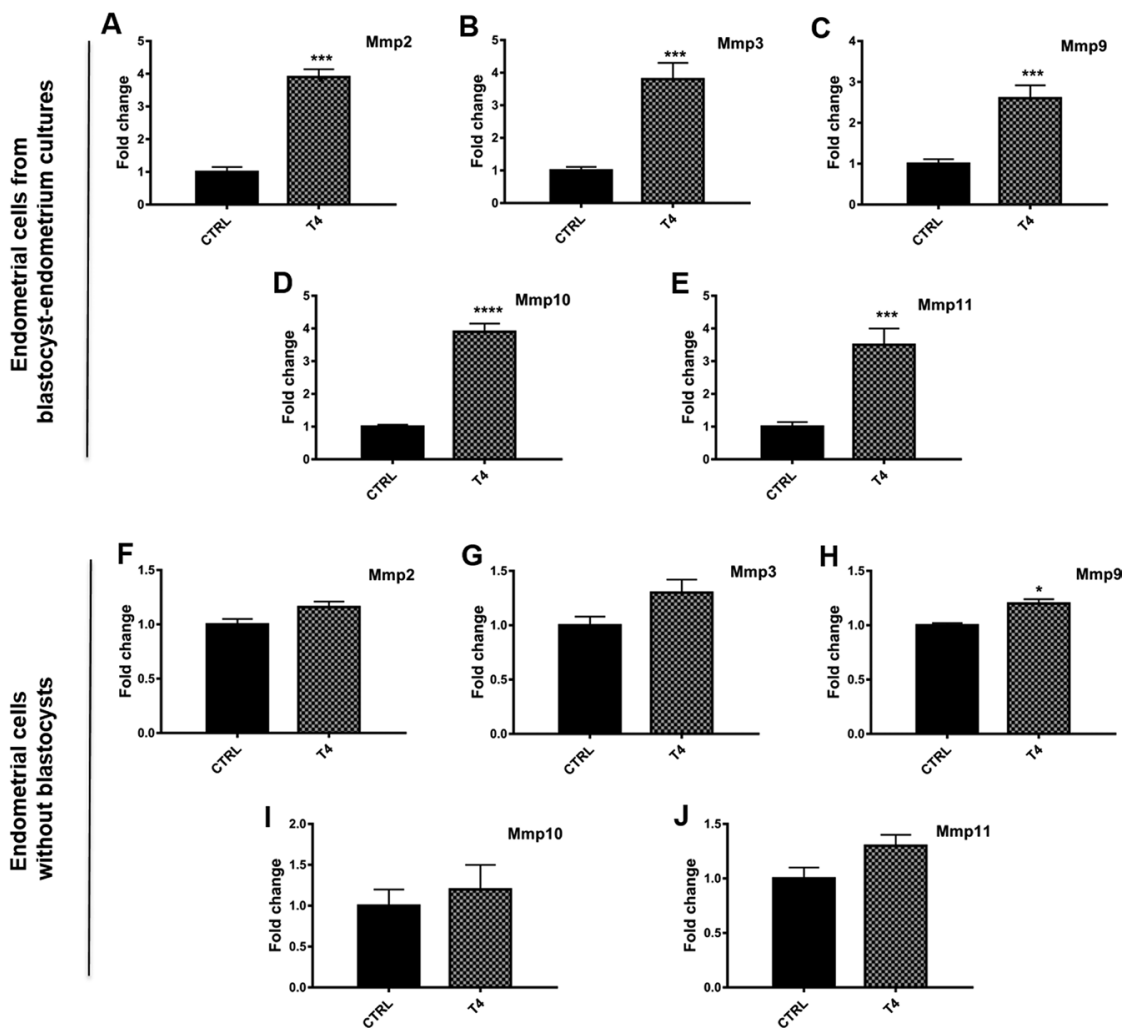

\begin{abstract}
Figure 8
TH induces a significant increase in the expression of MMPs in endometrial cells cultured in the presence of blastocysts. Relative expression of (A) Mmp2, (B) Mmp3, (C) Mmp9, (D) Mmp10 and (E) Mmp11 in endometrial cells co-cultured with blastocysts. Relative expression of (F) Mmp2, (G) Mmp3, (H) Mmp9, (I) Mmp10 and (J) Mmp11 in endometrial cells cultured without blastocysts. ${ }^{*} P \leq 0.05 ;{ }^{* *} P \leq 0.01 ; * * * P \leq 0.001$. Data are the mean of five independent experiments \pm S.E.
\end{abstract}

cultures with $\mathrm{T}_{4}$ significantly increases the percentage of hatching blastocyst after $16 \mathrm{~h} \quad(\mathrm{CTRL}=5.45 \pm 2.5$; $\left.\mathrm{T}_{4}=18.9 \pm 2.8\right) \quad$ and $\quad 24 \mathrm{~h} \quad(\mathrm{CTRL}=20.54 \pm 4.1$; $\left.\mathrm{T}_{4}=40.52 \pm 5.5\right)$, while no differences were observed after $48 \mathrm{~h} \quad\left(\mathrm{CTRL}=81.42 \pm 14.2 ; \mathrm{T}_{4}=97.9 \pm 2.1\right)$ (Fig. 6C). Interestingly, $\mathrm{T}_{4}$ supplementation of blastocyst cultures in the absence of endometrial feeder layer did not increase the percentage of hatched blastocysts at all time points studied (CTRL $16 \mathrm{~h}=10.4 \pm 3.3 ; \quad \mathrm{T}_{4} \quad 16 \mathrm{~h}=10.5 \pm 3.66$; CTRL $24 \mathrm{~h}=21.167 \pm 6.099 ; \mathrm{T}_{4} 24 \mathrm{~h}=23.267 \pm 6.96 ; \mathrm{CTRL}$ $\left.48 \mathrm{~h}=51.66 \pm 3.38 ; \quad \mathrm{T}_{4} \quad 48 \mathrm{~h}=50.933 \pm 2.69\right) \quad$ (Fig. 6D). Since the serine proteases Isp1 and Isp2 have been demonstrated to be important regulators of blastocyst hatching in mice (O'Sullivan et al. 2001, Sharma et al. 2006), we cultured blastocysts in the presence of $T_{4}$ on either endometrial feeder layer or alone for $16 \mathrm{~h}$ and then analyzed the expression of these two proteases by qRTPCR. When blastocysts were cultured on endometrial cells and treated with $\mathrm{T}_{4}$, the expression of Isp1 and Isp2 was significantly upregulated by about four-fold (Fig. 7A and B). Culture of blastocysts on plastic in the presence of $\mathrm{TH}$ induced a low but significant increase in the expression of Isp1, while it had no effect on Isp2 (Fig. 7C and D). Similar results were observed analyzing endometrial cells for the expression of Isp1 and Isp2 after 16h of culture. Remarkably, in endometrial cells co-cultured with blastocysts, $\mathrm{T}_{4}$ supplementation induced a significant increase in both Isp1 and Isp2 (Fig. 7E and F), while $\mathrm{T}_{4}$ supplementation of endometrial cells cultured without blastocysts induced a much less increase, which reached statistical significance only for Isp1 (Fig. 7G and H). We also investigated by qRT-PCR the endometrial expression of the major metalloproteinases expressed during the implantation window. When the endometrial cells were co-cultured for $16 \mathrm{~h}$ with blastocysts, $\mathrm{T}_{4}$ supplementation induced a significant three- to four-fold increase in all MMPs studied. Similarly to what observed for Isp1 and Isp2, supplementation of $\mathrm{T}_{4}$ induced a much lower increase in the expression of MMPs (which was statistically significant only for Mmp9) if endometrial cells were cultured without blastocysts (Fig. 8). These data suggest that $\mathrm{TH}$ regulates the bidirectional crosstalk between the receptive endometrium and the ready-to-implant embryo.

To investigate if $\mathrm{TH}$ might also be involved in blastocyst attachment and invasion of the endometrial tissue, blastocysts were cultured for $72 \mathrm{~h}$ either on endometrial cells or on plastic, with or without $\mathrm{T}_{4}$ supplementation. At the end of the culture, the number of blastocysts that attached and underwent outgrowth was counted, and the area occupied by the trophectodermal cells was measured. Our results show that $\mathrm{T}_{4}$ supplementation does not influence 
A

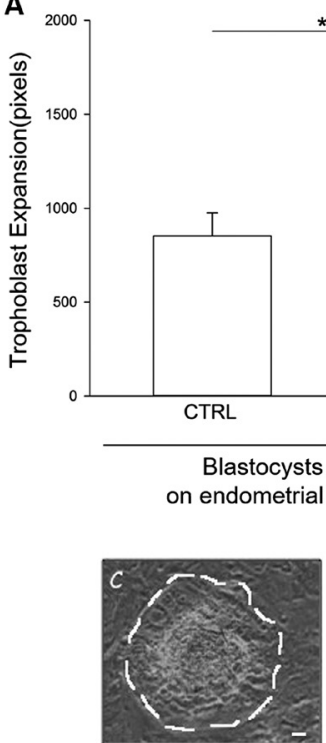

CTRL

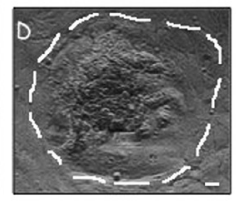

T4

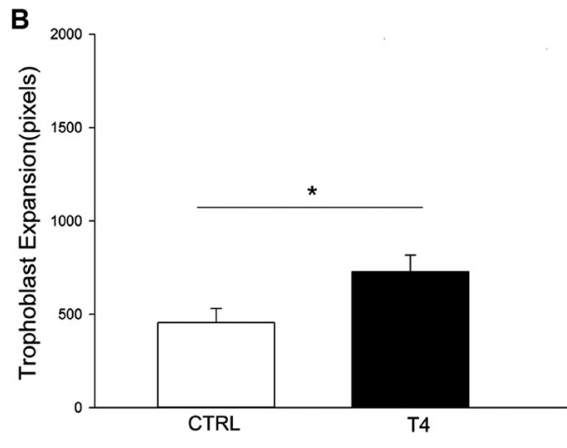

Blastocysts cultured without endometrial feeder-layer

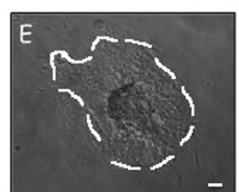

CTRL

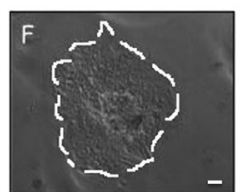

T4

\section{Figure 9}

TH is able to positively influence blastocyst outgrowth. (A and B) Quantification of the area covered by trophoectodermal cells in the presence $(A)$ or absence $(B)$ of the endometrial feeder layer. In three independent experiments, twenty randomly chosen blastocysts were measured for each condition. ( $C$ and $D$ ) Representative images of blastocyst outgrowth in (C) control and (D) TH-treated blastocystendometrium cell co-cultures; ( $\mathrm{E}$ and $\mathrm{F}$ ) blastocysts outgrowth in (E) control and (F) TH-treated blastocysts cultured without the feeder layer. Scale bar $50 \mu \mathrm{m} ;{ }^{*} P<0.05, * * P \leq 0.01$. blastocysts' attachment, as at the end of the culture, all blastocysts had adhered and exposed their inner cell mass; however, blastocyst outgrowth, measured as surface occupied by trophectodermal cells, was significantly increased in cultures supplemented with $\mathrm{TH}\left(\mathrm{CTRL}=1493 \pm 165 ; \mathrm{T}_{4}=2705 \pm 276\right.$ Pixels $)$. Increased outgrowth of the trophectoderm was also observed for blastocysts cultured with $\mathrm{T}_{4}$ on plastic $(\mathrm{CTRL}=579 \pm 149$; $\mathrm{T}_{4}=805 \pm 130.6$ Pixels), although the difference in the covered area between $\mathrm{T}_{4}$-treated and non-treated cultures was much lower than that measured after the outgrowth of blastocysts cultured on endometrial feeder cells (Fig. 9).

\section{Discussion}

Implantation and embryo development are finely regulated processes, characterized by highly orchestrated interactions between the competent-blastocyst and the maternal receptive endometrium. The hallmark events of implantation are represented by tissue remodeling and angiogenesis (Dey et al. 2004, Plaisier 2011), which are regulated by the activity of MMPs and MMP inhibitors (TIMPs), as well as activation of the Notch pathway. A clinical association between hypothyroidism and infertility and/or implantation failure has been extensively reported, although the molecular mechanism underlying this association remains unclear (Kilic et al. 2008, Stagnaro-Green \& Pearce 2012, Granfors et al. 2013, Colicchia et al. 2014).
To study the effect of $\mathrm{TH}$ in implantation and embryo development, we have used an in vivo model of hypothyroidism, by treating CD1-outbred mouse females with the thyroid peroxidase inhibitor methimazole (MMI). To date, few in vivo experimental models of hypothyroidism have been developed, which include treatment with MMI, sodium perchlorate, propylthiouracil (PTU) and the use of transgenic strains, e.g., MCT8 knockout mice. In the present study, to induce hypothyroidism in pregnant mice, the use of MMI was preferred to the use of transgenic strains. In fact, mouse models of hypothyroidism obtained after ablation of genes involved in TH pathway, such as MCT8 knockout mice, display severe phenotypes which complicates the analysis of pregnancy-related pathways (Trajkovic-Arsic et al. 2010). Under our experimental conditions, MMI was able to significantly decrease the levels of circulating TH. Hypothyroid pregnant females had a significantly reduced average number of pups/litter, clearly indicating that decreased maternal circulating levels of $\mathrm{TH}$ are able to affect implantation and/or embryo development, confirming the many clinical observations reported in humans. To identify the critical developmental stage at which hypothyroidism affects pregnancy outcome, we have killed pregnant females at implantation, at the early stages of placentation, and one day prior to birth, when organogenesis is completed. At implantation, we observed no statistically significant differences in the number of implantation sites between hypothyroid and euthyroid females, but we detected a higher (although non-significant) percentage of nonpregnant females in the hypothyroid group, suggesting 
the possibility that reduced levels of TH might affect ovulation and/or oocyte quality, impairing fertilization, or might regulate embryo-endometrium interaction. To further clarify this, we studied the expression of ISP1 and ISP2, two proteases that are key regulators of mouse embryo implantation, which are produced by both the blastocyst and the receptive endometrium and their action is indispensable for efficient implantation (O'Sullivan et al. 2001, Sharma et al. 2006, 2011). At implantation, levels of both ISP1 and ISP2 were significantly reduced in uteri from pregnant hypothyroid females compared to euthyroid females, suggesting that $\mathrm{TH}$ regulates the expression of factors involved in the preparation of the uterus to embryo implantation. However, our data do not rule out the possibility that TH might also regulate earlier stages of pre-implantation development, as well as oocyte maturation and fertilization. Further studies are needed to settle these points. Since implantation abnormalities may result in altered placentation and consequent embryo loss, we performed the gene expression analysis for genes involved in placental development at $10.5 \mathrm{dpc}$, a stage at which labyrinth is expanding and critical events of organogenesis are still ongoing, and $18.5 \mathrm{dpc}$, characterized mainly by fetal growth. In particular, we analyzed the expression of MMPs and TIMPs, which are important modulators of spongiotrophoblast migration into maternal decidua and of decidual extracellular matrix remodeling. Our results show an overall downregulation of MMPs and TIMPs at $10.5 \mathrm{dpc}$, and a significant downregulation of Timp3 at $18.5 \mathrm{dpc}$. We have also investigated activation of the Notch signaling pathway, a recognized key determinant of placental development. All Notch target genes studied were significantly downregulated at both 10.5 and $18.5 \mathrm{dpc}$. Altogether, our results point toward a role of $\mathrm{TH}$ in the regulation of many of the key events of placentation, including trophoblast invasion and remodeling of decidual tissue, and possibly angiogenesis. Interestingly, morphological observation of the pregnant uteri demonstrated that at $10.5 \mathrm{dpc}$, the number of embryos per female was similar between euthyroid and hypothyroid females, although a slight increase in the number of resorption was detected. On the contrary, a significant reduction in the number of fetuses per dam was observed at $18.5 \mathrm{dpc}$ in hypothyroid females, and was associated with significantly reduced fetal crowrump length and weight and increased placental weight, suggesting that low levels of maternal TH induce in utero growth restriction and that compensatory placental expansion occurs. These results indicate that TH may play a critical role on fetal development in a window comprised between 10.5 and birth, and that possible alteration in placental development may be the underlying causal mechanism.

Altogether, our in vivo study suggests that hypothyroidism may have a dual effect on pregnancy, by influencing implantation at very early stages of gestation, and by regulating placental development at later stages.

We further investigated the role of TH in implantation by culturing blastocyst and endometrial cells in vitro to recapitulate embryo implantation. After monitoring the cultures up to $48 \mathrm{~h}$, we observed that medium supplementation with $\mathrm{TH}$ significantly increased the number of hatching blastocysts already after $16 \mathrm{~h}$, possibly as a consequence of the observed upregulation of the two main proteases involved in mouse blastocyst hatching, namely Isp1 and Isp2. A translational application of these results might be foreseen in the development of complex media for application in in vitro reproductive technologies. Interestingly, we observed that the co-culture of blastocysts and endometrial feeder cells is indispensable for TH-mediated induction of Isp1 and 2 and other implantation relevant proteases, and for the increased hatching, suggesting that $\mathrm{TH}$ is involved in the bidirectional crosstalk between the competent blastocyst and the receptive endometrium at the time of implantation. The observed endometrial-dependent effect on blastocyst hatching might be the consequence of TH-stimulated release of proteases by the endometrial cells, which may act on both the endometrium itself and the blastocyst. On the other hand, we cannot exclude that $\mathrm{TH}$ stimulation of endometrial cells might result in the expression of factors other than proteases (e.g. LIF). The transcriptome analysis of TH-stimulated endometrial cells would give insights into this respect. At further support to the hypothesis of $\mathrm{TH}$ as a regulator of the bidirectional crosstalk between the endometrium and the blastocyst, we evaluated the ability of TH to modulate the initial phase of implantation. To this end, we cultured blastocysts in vitro and studied their outgrowth on the endometrial feeder layer or on plastic. After $72 \mathrm{~h}$ of culture, trophectodermal cells attached and expanded on both endometrial cells and plastic, mimicking in vitro the invasion of maternal tissue; however, the surface occupied by trophectodermal cells was greater in the presence of the feeder layer. Of note, $\mathrm{T}_{4}$ was capable of significantly increasing the outgrowth of trophectoderm cells under both culture conditions.

In conclusion, our results identify molecular mechanisms regulated by $\mathrm{TH}$ that may link hypothyroidism to implantation failure and recurrent miscarriage, events often observed under 
this pathological condition, offering a mechanistic explanation to the clinical observations.

\section{Declaration of interest}

The authors declare that there is no conflict of interest that could be perceived as prejudicing the impartiality of the research reported.

\section{Funding}

This work was partially supported by IBSA Institute Biochimique SA (IBSA Pambi-Noranco, CH).

\section{Author contribution statement}

$D P$ and $E$ B performed most of the experiments; $M M$ and $R$ B helped in some of the experiments; A C and A S helped in the interpretation of the data and critically read the manuscript; $\mathrm{M} C$ helped in the interpretation of the data; S U and C M contributed to the study design and to the interpretation of the results; $L \mathrm{C}$ designed the study, interpreted the data and wrote the manuscript.

\section{References}

Abalovich M, Gutierrez S, Alcaraz G, Maccallini G, Garcia A \& Levalle O 2002 Overt and subclinical hypothyroidism complicating pregnancy. Thyroid 12 63-68. (https://doi.org/10.1089/105072502753451986)

Aghajanova L, Stavreus-Evers A, Lindeberg M, Landgren BM, Skjoldebrand Sparre L \& Hovatta O 2011 Thyroid-stimulating hormone receptor and thyroid hormone receptors are involved in human endometrial physiology. Fertility and Sterility 95 230-237. (https://doi.org/10.1016/j.fertnstert.2010.06.079)

Aplin JD, Haigh T, Lacey H, Chen CP \& Jones CJ 2000 Tissue interactions in the control of trophoblast invasion. Journal of Reproduction and Fertility: Supplement 55 57-64.

Ashitaka Y, Maruo M, Takeuchi Y, Nakayama H \& Mochizuki M 1988 3,5,3'-triiodo-L-thyronine binding sites in nuclei of human trophoblastic cells. Endocrinologia Japonica 35 197-206. (https://doi. org/10.1507/endocrj1954.35.197)

Ashkar FA, Bartlewski PM, Singh J, Malhi PS, Yates KM, Singh T \& King WA 2010 Thyroid hormone concentrations in systemic circulation and ovarian follicular fluid of cows. Experimental Biology and Medicine 235 215-221. (https://doi.org/10.1258/ebm.2009.009185)

Banovac K, Ryan EA \& O'Sullivan MJ 1986 Triiodothyronine (T3) nuclear binding sites in human placenta and decidua. Placenta 7 543-549. (https://doi.org/10.1016/S0143-4004(86)80140-0)

van den Boogaard E, Vissenberg R, Land JA, van Wely M, van der Post JA, Goddijn M \& Bisschop PH 2011 Significance of (sub)clinical thyroid dysfunction and thyroid autoimmunity before conception and in early pregnancy: a systematic review. Human Reproduction Update 17 605-619. (https://doi.org/10.1093/humupd/dmr024)

Casey BM, Dashe JS, Wells CE, McIntire DD, Byrd W, Leveno KJ \& Cunningham FG 2005 Subclinical hypothyroidism and pregnancy outcomes. Obstetrics and Gynecology 105 239-245. (https://doi. org/10.1097/AOG.0b013e318240de6a)

Chan S \& Kilby MD 2000 Thyroid hormone and central nervous system development. Journal of Endocrinology 165 1-8. (https://doi. org/10.1677/joe.0.1650001)

Chan S, Kachilele S, Hobbs E, Bulmer JN, Boelaert K, McCabe CJ, Driver PM, Bradwell AR, Kester M, Visser TJ, et al. 2003 Placental iodothyronine deiodinase expression in normal and growth-restricted human pregnancies. Journal of Clinical Endocrinology and Metabolism 88 4488-4495. (https://doi.org/10.1210/jc.2003-030228)

Colicchia M, Campagnolo L, Baldini E, Ulisse S, Valensise H \& Moretti C 2014 Molecular basis of thyrotropin and thyroid hormone action during implantation and early development. Human Reproduction Update 20 884-904. (https://doi.org/10.1093/ humupd/dmu028)

Contempre B, Jauniaux E, Calvo R, Jurkovic D, Campbell S \& de Escobar GM 1993 Detection of thyroid hormones in human embryonic cavities during the first trimester of pregnancy. Journal of Clinical Endocrinology and Metabolism 77 1719-1722. (https://doi. org/10.1210/jcem.77.6.8263162)

Costa NN, Cordeiro MS, Silva TV, Sastre D, Santana PP, Sá AL, Sampaio RV, Santos SS, Adona PR, Miranda MS, et al. 2013 Effect of triiodothyronine on developmental competence of bovine oocytes. Theriogenology 80 295-301. (https://doi.org/10.1016/j. theriogenology.2013.04.011)

Dey SK, Lim H, Das SK, Reese J, Paria BC, Daikoku T \& Wang H 2004 Molecular cues to implantation. Endocrine Reviews 25 341-373. (https://doi.org/10.1210/er.2003-0020)

Dittrich R, Beckmann MW, Oppelt PG, Hoffmann I, Lotz L, Kuwert T \& Mueller A 2011 Thyroid hormone receptors and reproduction. Journal of Reproductive Immunology 90 58-66. (https://doi.org/10.1016/j. jri.2011.02.009)

Granfors M, Åkerud H, Berglund A, Skogö J, Sundström-Poromaa I \& Wikström AK 2013 Thyroid testing and management of hypothyroidism during pregnancy: a population-based study. Journal of Clinical Endocrinology and Metabolism 98 2687-2692. (https://doi. org/10.1210/jc.2013-1302)

Idris I, Srinivasan R, Simm A \& Page RC 2005 Maternal hypothyroidism in early and late gestation: effects on neonatal and obstetric outcome. Clinical Endocrinology 63 560-565. (https://doi.org/10.1111/j.13652265.2005.02382.x)

Kaneko Y, Day ML \& Murphy CR 2013 Uterine epithelial cells: serving two masters. International Journal of Biochemistry and Cell Biology $\mathbf{4 5}$ 359-363. (https://doi.org/10.1016/j.biocel.2012.10.012)

Kilby MD, Verhaeg J, Gittoes N, Somerset DA, Clark PM \& Franklyn JA 1998 Circulating thyroid hormone concentrations and placental thyroid hormone receptor expression in normal human pregnancy and pregnancy complicated by intrauterine growth restriction (IUGR). Journal of Clinical Endocrinology and Metabolism 83 2964-2971. (https://doi.org/0.1210/jcem.83.8.5002)

Kilby MD, Barber K, Hobbs E \& Franklyn JA 2005 Thyroid hormone action in the placenta. Placenta 26 105-113. (https://doi. org/10.1016/j.placenta.2004.08.004)

Kilic S, Tasdemir N, Yilmaz N, Yuksel B, Gul A \& Batioglu S 2008 The effect of anti-thyroid antibodies on endometrial volume, embryo grade and IVF outcome. Gynecological Endocrinology 24 649-655. (https://doi.org/10.1080/09513590802531112)

Krassas GE, Poppe K \& Glinoer D 2010 Thyroid function and human reproductive health. Endocrine Reviews 31 702-755. (https://doi. org/10.1210/er.2009-0041)

Kumar R \& Chaudhuri BN 1989 Altered maternal thyroid function: fetal and neonatal development of rat. Indian Journal of Physiology and Pharmacology 33 233-238.

LaFranchi SH, Haddow JE \& Hollowell JG 2005 Is thyroid inadequacy during gestation a risk factor for adverse pregnancy and developmental outcomes? Thyroid 15 60-71. (https://doi.org/10.1089/ thy.2005.15.60)

Luewan S, Chakkabut P \& Tongsong T 2011 Outcomes of pregnancy complicated with hyperthyroidism: a cohort study. Archives of Gynecology and Obstetrics 283 243-247. (https://doi.org/10.1007/ s00404-010-1362-z)

Maruo T, Matsuo H \& Mochizuki M 1991 Thyroid hormone as a biological amplifier of differentiated trophoblast function in early pregnancy. Acta Endocrinologica 125 58-66. 
Mestman JH 2004 Hyperthyroidism in pregnancy. Best Practice and Research: Clinical Endocrinology and Metabolism 18 267-288. (https:// doi.org/10.1016/j.beem.2004.03.005)

Mishra A \& Seshagiri PB 2000 Heparin binding-epidermal growth factor improves blastocyst hatching and trophoblast outgrowth in the golden hamster. Reproductive Biomedicine Online 1 87-95. (https://doi. org/10.1016/S1472-6483(10)61945-1)

Moeller LC \& Broecker-Preuss M 2011 Transcriptional regulation by nonclassical action of thyroid hormone. Thyroid Research $\mathbf{4}$ (Supplement 1) S6. (https://doi.org/10.1186/1756-6614-4-S1-S6)

Nazarpour S, Ramezani Tehrani F, Simbar M \& Azizi F 2015 Thyroid dysfunction and pregnancy outcomes. Iranian Journal of Reproductive Medicine 13 387-396

Obregon MJ, Mallol J, Pastor R, Morreale de Escobar G \& Escobar del Rey F1984 L- thyroxine and 3,5,3'-triiodo-L-thyronine in rat embryos before onset of fetal thyroid function. Endocrinology 114 305-307. (https://doi.org/10.1210/endo-114-1-305)

O'Sullivan CM, Rancourt SL, Liu SY \& Rancourt DE 2001 A novel murine tryptase involved in blastocyst hatching and outgrowth. Reproduction 122 61-71.

Petersen CG, Mauri AL, Baruffi RL, Oliveira JB, Massaro FC, Elder K \& Franco JG Jr 2005 Implantation failures: success of assisted hatching with quarter-laser zona thinning. Reproductive Biomedicine Online 10 224-229. (https://doi.org/10.1016/S1472-6483(10)60944-3)

Pillar N, Levy A, Holcberg G \& Sheiner E 2010 Pregnancy and perinatal outcome in women with hyperthyroidism. International Journal of Gynaecology and Obstetrics 108 61-64. (https://doi.org/10.1016/j. ijgo.2009.08.006)

Plaisier M 2011 Decidualisation and angiogenesis. Best Practice and Research: Clinical Obstetrics and Gynaecology 25 259-271. (https://doi. org/10.1016/j.bpobgyn.2010.10.011)

Schwartz HL, Trence D, Oppenheimer JH, Jiang NS \& Jump DB 1983 Distribution and metabolism of L- and D-triiodothyronine (T3) in the rat: preferential accumulation of L-T3 by hepatic and cardiac nuclei as a probable explanation of the differential biological potency of T3 enantiomers. Endocrinology 113 1236-1243. (https://doi.org/10.1210/ endo-113-4-1236)
Seshagiri PB, Mishra A, Ramesh G \& Rao RP 2002 Regulation of periattachment embryo development in the golden hamster: role of growth factors. Journal of Reproductive Immunology 53 203-213. (https://doi.org/10.1016/S0165-0378(01)00086-9)

Sharma N, Liu S, Tang L, Irwin J, Meng G \& Rancourt DE 2006 Implantation serine proteinases heterodimerize and are critical in hatching and implantation. BMC Developmental Biology 6 61. (https:// doi.org/10.1186/1471-213X-6-61)

Sharma N, Kumar R, Renaux B, Saifeddine M, Nishikawa S, Mihara K, Ramachandran R, Hollenberg MD \& Rancourt DE 2011 Implantation serine proteinase 1 exhibits mixed substrate specificity that silences signaling via proteinase- activated receptors. PLoS ONE 6 e27888. (https://doi.org/10.1371/journal.pone.0027888)

Stagnaro-Green A \& Pearce E 2012 Thyroid disorders in pregnancy. Nature Reviews: Endocrinology 8 650-658. (https://doi.org/10.1038/ nrendo.2012.171)

Staun-Ram E \& Shalev E 2005 Human trophoblast function during the implantation process. Reproductive Biology and Endocrinology 356. (https://doi.org/10.1186/1477-7827-3-56)

Thorpe-Beeston JG, Nicolaides KH, Felton CV, Butler J \& McGregor AM 1991 Maturation of the secretion of thyroid hormone and thyroid-stimulating hormone in the fetus. New England Journal of Medicine 324 532-536. (https://doi.org/10.1056/ NEJM199102213240805)

Trajkovic-Arsic M, Müller J, Darras VM, Groba C, Lee S, Weih D, Bauer K, Visser TJ \& Heuer H 2010 Impact of monocarboxylate transporter-8 deficiency on the hypothalamus-pituitary-thyroid axis in mice. Endocrinology 151 5053-5062. (https://doi.org/10.1210/ en.2010-0593)

Vu TKH, Liu RW, Haaksma CJ, Tomasek JJ \& Howard EW 1997 Identification and cloning of the membrane-associated serine protease, hepsin, from mouse preimplantation embryos. Journal of Biological Chemistry 272 31315-31320. (https://doi.org/10.1074/ jbc.272.50.31315)

Watson ED \& Cross JC 2005 Development of structures and transport functions in the mouse placenta. Physiology 20 180-193. (https://doi. org/10.1152/physiol.00001.2005)

Received in final form 8 September 2017

Accepted 9 October 2017

Accepted Preprint published online 9 October 2017 